\title{
ZAŁOŻENIA BUDOWY MODELU WYDAJNOŚCI PRACY ROBOTNIKÓW BUDOWLANYCH
}

\author{
Jarosław Malara ${ }^{\bowtie}$ \\ Wydział Inżynierii Lądowej, Politechnika Krakowska, Kraków
}

\begin{abstract}
STRESZCZENIE
W artykule podjęto problematykę wydajności czasu pracy robotników budowlanych, zależnej od zróżnicowanych czynników. Przedstawiono różne sposoby definiowania samej wydajności pracy i stwierdzono, że najkorzystniejsza definicja jest porównaniem wypracowanego efektu z założonym normatywem. Przedstawiono także istniejące klasyfikacje czynników wpływających na wydajność pracy i oceniono ich uniwersalność. W bezpośrednim porównaniu uniwersalna okazała się jedna z klasyfikacji. Wynikiem pracy było przedstawienie autorskiego podejścia do matematycznej parametryzacji czynników wpływających na wydajność pracy robotników budowlanych.
\end{abstract}

Słowa kluczowe: model, wydajność pracy, robotnicy budowlani, czynniki

\section{WSTĘP}

Znaczenie wydajności pracy $\mathrm{w}$ procesach produkcyjnych, w tym m.in. w budownictwie, jako pierwszy dostrzegł F.W. Taylor (Kieżun, 1980). Dzięki swojemu, jak na ówczesne czasy, nowatorskiemu podejściu stał się ojcem nurtu nazwanego od jego nazwiska tayloryzmem. Wpływ jego działalności naukowej jest dostrzegany we współczesnych koncepcjach zarządzania pracownikami (Ćwiklicki, 2011). W najogólniejszym ujęciu tayloryzm zakłada podział wykonywanych przez robotników czynności na drobniejsze elementy składowe, które następnie są analizowane z wykorzystaniem jednej z technik badania czasu pracy - chronometrażu. Analiza czynności składowych pozwala na wyciąganie wniosków i ograniczanie czynności zbędnych. Współczesne podejście do badania czasu pracy jest w dużym stopniu oparte na założeniach tayloryzmu.

Do analizy zagadnienia konieczne jest zdefiniowanie pojęcia wydajności pracy. W trakcie analizy literatury można zauważyć duże rozbieżności w przyjmowanych definicjach. Część publikacji traktuje wydajność pracy jako stosunek ilości wykonanej pracy do nakładów pracy zakładanych w normie (Koźmiński i Piotrowski, red., 1999, Griffin, 2004). Istnieją również zdania, że wydajność pracy jest miarą wartości produkcji wytworzonej w czasie przez jednego pracującego (Rowiński, 1982, Dyżewski, 1989). Największy problem pojawia się podczas próby zdefiniowania jednostki, w której wydajność pracy powinna być przedstawiana. Kwestia ta została skutecznie rozstrzygnięta przez niektórych ekonomistów (Staworzyński, 2017) oraz Główny Urząd Statystyczny (2016), którzy traktują wydajność pracy jako wskaźnik porównawczy. Definiują to pojęcie jako stosunek rzeczywiście wykonanych dóbr w określonym czasie w stosunku do przyjętego normatywu, wyrażając rezultat bezjednostkowo lub procentowo. Takie podejście w najogólniejszym ujęciu oznacza stopień wykonania zakładanej normy, gdzie 1 (100\%) oznacza pracę zgodnie z wartością porównawczą, często średnią.

\footnotetext{
凶jmalara@izwbit.pk.edu.pl
} 
Niewątpliwą korzyścią płynącą z przyjęcia takiej definicji jest możliwość bezpośredniej oceny stopnia realizacji założeń pracowników i porównania ich wydajności przy różnych stanowiskach roboczych. Pracownik osiagający wydajność $115 \%$ wykonuje pracę, przekraczając przyjętą normę, natomiast $90 \%$ oznacza realizację zadań poniżej poziomu odniesienia (często oczekiwań). Z uwagi na uniwersalność i przejrzystość interpretacji wyników w niniejszym artykule przyjęto tę właśnie definicję wydajności czasu pracy w odniesieniu do analizy robotników budowlanych.

Celem artykułu jest przedstawienie założeń budowy matematycznego modelu opisującego wydajność czasu pracy robotników budowlanych, uwzględniającego wpływ zidentyfikowanych czynników.

\section{IDENTYFIKACJA I KLASYFIKACJA CZYNNIKÓW WPŁYWAJĄCYCH NA WYDAJNOŚĆ PRACY}

W trakcie realizacji robót budowlanych na pracownika nieustannie oddziałują różnego rodzaju czynniki. Mają one wpływ na osiaganą przez niego wydajność. Jednym z problemów, jakie wynikają z analizy literatury, jest ich zidentyfikowanie i sklasyfikowanie. Jedną z prób podjęli Radziszewska-Zielina, Sobotka, Plebankiewicz i Zima (2013). Odnieśli się oni co prawda do czynników oddziałujących na układ operator-maszyna, ale można je uogólnić na parametry związane z maszyną, operatorem i otoczeniem. W sposób szczegółowy czynniki te przedstawiono w tabeli 1 .

Tabela 1. Parametry oddziałujące na wydajność układu operator-maszyna do robót ziemnych (Radziszewska-Zielina i in., 2013)

Table 1. The parameters affecting for the performance of the operator-machine earthmoving (Radziszewska-Zielina et al., 2013)

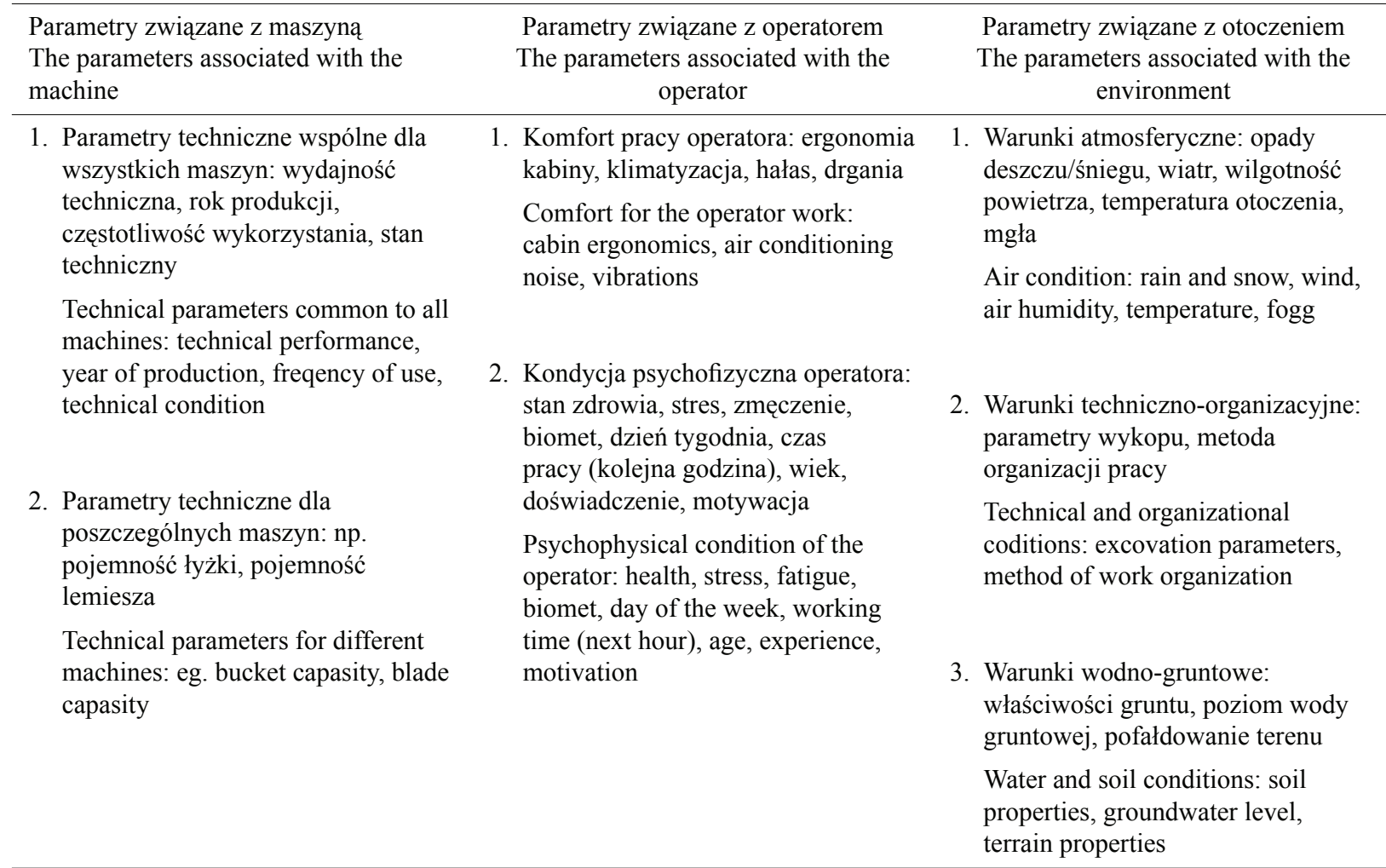


Parametry zidentyfikowane w tabeli 1 można podzielić na dwie zasadnicze kategorie: uniwersalne - wspólne dla wszystkich robót budowlanych, i szczególne - charakterystyczne dla wybranych robót. Zdaniem autora do grona czynników uniwersalnych należy zaliczyć: ergonomię, hałas, stan zdrowia, stres, zmęczenie, biomet, dzień tygodnia, czas pracy, wiek, doświadczenie, motywację, opady, wiatr, wilgotność powietrza, temperaturę otoczenia i metodę organizacji pracy. Wśród czynników szczególnych należy wskazać: wydajność techniczną maszyny, rok produkcji, częstotliwość jej wykorzystania, stan techniczny, pojemność łyżki, pojemność lemiesza, klimatyzację, drgania, parametry wykopu, właściwości gruntu, poziom wody gruntowej i pofałdowanie terenu. Autor artykułu w swojej pracy badawczej i rozważaniach nad wydajnością pracy wykorzystał identyfikację czynników zaliczonych do grupy uniwersalnych.

Bardziej ogólna klasyfikacja została przedstawiona przez Hoła i Mrozowicz (2003). Ujęto w niej 22 czynniki, które zostały przypisane do 4 podstawowych grup: techniczne, organizacyjne, środowisko pracy i cechy indywidualne robotników. Pełny podział został ujęty w tabeli 2.

Tabela 2. Klasyfikacja czynników mających wpływ na wielkość norm czasu pracy (Hoła i Mrozowicz, 2003)

Table 2. Classification of factors influencing the size of the working time standard (Hoła and Mrozowicz, 2003)

\begin{tabular}{|c|c|c|c|c|}
\hline \multicolumn{5}{|c|}{$\begin{array}{l}\text { Czynniki wpływu } \\
\text { Impact of the factors }\end{array}$} \\
\hline \multirow{2}{*}{$\begin{array}{l}\text { Techniczne } \\
\text { Technical }\end{array}$} & \multirow{2}{*}{$\begin{array}{l}\text { Organizacyjne } \\
\text { Organizational }\end{array}$} & \multirow{2}{*}{$\begin{array}{c}\text { Środowiska pracy } \\
\text { Working environment }\end{array}$} & \multicolumn{2}{|c|}{$\begin{array}{l}\text { Cechy indywidualne robotników } \\
\text { Individual characteristic of workers }\end{array}$} \\
\hline & & & $\begin{array}{c}\text { cechy fizyczne } \\
\text { physical properties }\end{array}$ & $\begin{array}{l}\text { cechy psychiczne } \\
\text { psychological } \\
\text { properties }\end{array}$ \\
\hline $\begin{array}{l}\text { Pofałdowanie terenu } \\
\text { Terain properties }\end{array}$ & $\begin{array}{l}\text { metoda wykonywania } \\
\text { pracy } \\
\text { working method }\end{array}$ & $\begin{array}{l}\text { warunki } \\
\text { atmosferyczne } \\
\text { air condition }\end{array}$ & $\begin{array}{l}\text { siła } \\
\text { strength }\end{array}$ & $\begin{array}{l}\text { motywacja do pracy } \\
\text { work motivation }\end{array}$ \\
\hline $\begin{array}{l}\text { Typ maszyny } \\
\text { i urządzenia } \\
\text { Type of machines } \\
\text { and equipment }\end{array}$ & $\begin{array}{l}\text { podział prac } \\
\text { work distribution }\end{array}$ & $\begin{array}{l}\text { szkodliwe } \\
\text { i niebezpieczne } \\
\text { otoczenie: hałas, } \\
\text { oświetlenie, } \\
\text { zanieczyszczenia, } \\
\text { praca na wysokości } \\
\text { harmful and danger- } \\
\text { ous environment: } \\
\text { noise, lighting, pollu- } \\
\text { tion, work at heights }\end{array}$ & $\begin{array}{l}\text { umiejętność } \\
\text { koordynowania } \\
\text { ruchów } \\
\text { ability to oordinate } \\
\text { movements }\end{array}$ & $\begin{array}{l}\text { łatwość } \\
\text { dostosowywania } \\
\text { się do zmiennych } \\
\text { warunków pracy } \\
\text { ability to adapt to } \\
\text { changing working } \\
\text { condition }\end{array}$ \\
\hline
\end{tabular}

W stosunku do klasyfikacji przedstawionej w tabeli 1 zdecydowanie więcej czynników ujętych w tabeli 2 ma charakter uniwersalny. Największym mankamentem tego podziału jest jednak ujęcie w nim trudno mierzalnych i opisywalnych czynników, jak np. jakość produkcji. 
Na podstawie literatury i przedstawionych wcześniej klasyfikacji Plebankiewicz, Juszczyk i Malara (2014) dokonali identyfikacji czynników wpływających na wydajność pracy robotników budowlanych. Szczegóły zostały przedstawione w tabeli 3 .

Tabela 3. Podział czynników wpływających na wydajność (Plebankiewicz i in., 2014)

Table 3. Classification of the factors affecting the performance (Plebankiewicz et al., 2014)

\begin{tabular}{|c|c|}
\hline Grupa czynników - Group of factors & Czynniki - Factors \\
\hline $\begin{array}{l}\text { Czas spędzany poza pracą } \\
\text { Time spent outside of work }\end{array}$ & $\begin{array}{l}\text { odpowiednia długość odpoczynku - adequate lenght of rest } \\
\text { absencja pracownika - absenteeism of employer } \\
\text { czas spędzony z rodziną (WLB) - work life balance }\end{array}$ \\
\hline $\begin{array}{l}\text { Warunki atmosferyczne } \\
\text { Atmospheric conditions }\end{array}$ & $\begin{array}{l}\text { biomet - biomet } \\
\text { temperatura - temperature } \\
\text { wilgotność - humidity } \\
\text { opady - precitipation } \\
\text { ekstremalne warunki pracy (temp. i wilg.) - extreme work conditions } \\
\text { (temerature and humidity) }\end{array}$ \\
\hline $\begin{array}{l}\text { Kondycja psychofizyczna } \\
\text { Psychophysical condition }\end{array}$ & $\begin{array}{l}\text { stres - stress } \\
\text { zmęczenie - tiredness } \\
\text { stan zdrowia - halth } \\
\text { wiek - age } \\
\text { regeneracja sił - regeneration }\end{array}$ \\
\hline $\begin{array}{l}\text { Organizacja i kierowanie pracownikiem } \\
\text { Organization and management of worker }\end{array}$ & $\begin{array}{l}\text { ergonomia - ergonomy } \\
\text { hałas - noise } \\
\text { długość zmiany roboczej - lenght of working time } \\
\text { płaca - salary } \\
\text { organizacja pracy i stanowisk roboczych - organization of working } \\
\text { and workers front }\end{array}$ \\
\hline $\begin{array}{l}\text { Pozostałe czynniki } \\
\text { Other factors }\end{array}$ & $\begin{array}{l}\text { dzień tygodnia - day of the week } \\
\text { doświadczenie - experience } \\
\text { adaptacja do nowych warunków pracy lub nowej technologii - adaptation } \\
\text { to new work conditio or new technology }\end{array}$ \\
\hline
\end{tabular}

Przedstawione w tabeli 3 czynniki są najbardziej uniwersalnym zestawieniem spośród przytoczonych w niniejszym artykule. Ujęto w nim 21 czynników, które można zidentyfikować w przypadku każdej roboty budowlanej w kontekście prowadzenia badań nad wydajnością pracy. Do dalszych rozważań wykorzystano właśnie tę klasyfikację.

\section{PARAMETRYZACJA CZYNNIKÓW}

Jednym z problemów, na które autor natrafił podczas analizowania czynników wpływających na wydajność pracy robotników budowlanych, był ich matematyczny opis. Należy zwrócić uwagę, że poszczególne zidentyfikowane i sklasyfikowane $\mathrm{w}$ tabeli 3 czynniki występują w różnych jednostkach, np. temperatura $-{ }^{\circ} \mathrm{C}$, wiek - lata, hałas - dB, a część można opisać jedynie lingwistycznie: organizacja pracy i stanowisk roboczych czy stan zdrowia. Autor postanowił zmierzyć się z tym problemem i przedstawiać własne rozwiązanie. 
Ciekawą koncepcję podejścia do matematycznego modelowania procesów budowlanych opisano w jednej z publikacji (Ibadov i Kulejewski, 2010). Wykorzystuje ona teorię zbiorów rozmytych do rozwiązania przedstawionego problemu. O słuszności przyjętej koncepcji świadczy wykorzystanie podejścia w innych, podobnych zagadnieniach (Tah i Car, 2000, Chao, 2007; Konior, 2007; Plebankiewicz, 2012). Elementy logiki rozmytej bardzo dobrze wpasowują się w możliwość przekształcenia zmiennych lingwistycznych na wartości ostre. Zgodnie z jej założeniami, otrzymany rezultat zawiera się $\mathrm{w}$ przedziale $<0,1>$, co czyni ją również łatwą do implementacji w postaci aplikacji informatycznej. W dużym uproszczeniu, logika rozmyta może pozwolić na przyporządkowanie analizowanemu czynnikowi tzw. stopnia przynależności do wcześniej określonego zbioru. W niniejszym artykule zdefiniowano zbiór wysokich wydajności, w którym czynnik w pełni korzystnie wpływa na wydajność pracy robotników budowlanych. Przyporządkowanie czynnikom wartości stopnia przynależności do tego zbioru nazwano tu parametryzacją.

Pierwszy przykład zastosowania logiki rozmytej do opisu czynników dotyczy stresu. Jego negatywny wpływ został przedstawiony m.in. w publikacji Hsie (2009). Wśród przyczyn stresu należy wyróżnić m.in.:

- monotonię pracy, zbyt długo powtarzane czynności powodują irytację pracowników,

- za dużą ilość obowiązków, nieustanne zwiększanie wymagań podczas wykonywanej pracy i nakładanie zbyt wielu obowiązków powoduje przeciążenie psychiczne robotników,

- brak możliwości rozwoju, pracownicy nie posiadają perspektyw, w związku z czym praca powoduje frustrację, a ta z kolei jest przyczyną stresu,

- relacje interpersonalne, konflikty wewnątrz zespołu oraz nieprzyjemny i nieuprzejmy sposób komunikowania się może powodować złą atmosferę, która również zwiększa stres pracowników,

- problemy osobiste, należy podkreślić oddziaływanie życia prywatnego na pracę, co w przypadku kłopotów wpływa na zdenerwowanie pracowników.

Do oceny lingwistycznej czynnika przyjęta została pięciostopniowa skala Likerta (Gatignon, 2003). Pozwoliła ona na opisanie stresu za pomocą następujących określeń: bardzo duży, duży, umiarkowany, mały, bardzo mały. Interpretacja graficzna tego zagadnienia znajduje się na rysunku 1.

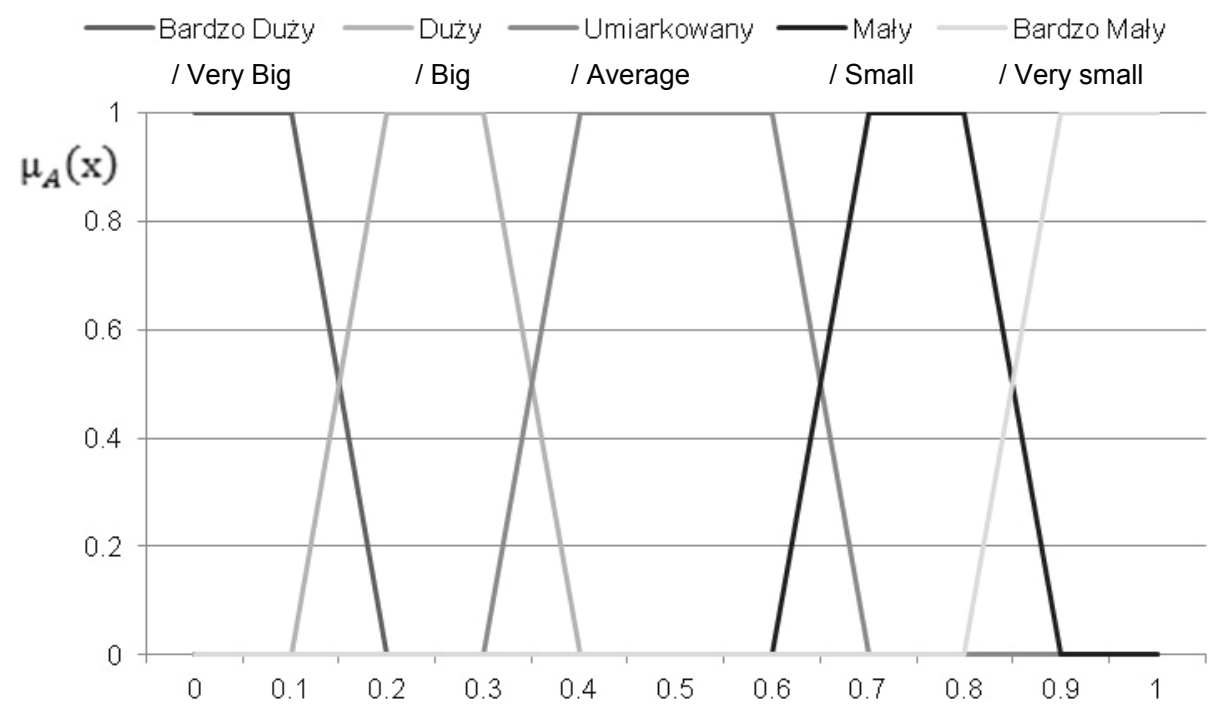

Rys. 1. Graficzna interpretacja rozmyta wartości lingwistycznych czynnika stres (Plebankiewicz, 2012)

Fig. 1. Graphic interpretation of fuzzy linguistic factor stress (Plebankiewicz, 2012) 
Innym przykładem parametryzacji jest dzień tygodnia. $\mathrm{Z}$ uwagi na występujące braki w literaturze przeprowadzono badania własne, których wyniki przedstawiono w artykule (Malara, 2014). Trzymiesięczne obserwacje pracowników budowlanych odbywały się na jednej z warszawskich budów. Obserwowane prace dotyczyły montażu okładzin klatek schodowych. Z całego badania wyodrębniono trzy czynności składowe: montaż schodów, wyrównanie spoczników oraz układanie spoczników, które zostały poddane dalszej analizie. Zbiorcze, średnie wartości osiągniętych przez pracowników efektów pracy przedstawiono w tabeli 4.

Tabela 4. Średnie efekty pracy w poszczególnych dniach tygodnia (Malara, 2014)

Table 4. Average effects of work on each day of the week (Malara, 2014)

\begin{tabular}{|c|c|c|c|c|c|c|c|}
\hline $\begin{array}{l}\text { Średnie efekty pracy } \\
\text { Average effects of work }\end{array}$ & 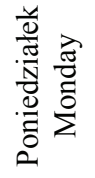 & 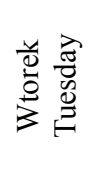 & 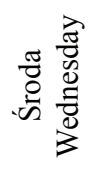 & 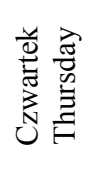 & 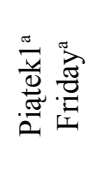 & 离兽 & 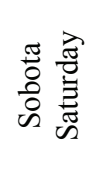 \\
\hline $\begin{array}{l}\text { Montaż schodów }\left[\mathrm{m} \cdot \mathrm{r}-\mathrm{g}^{-1}\right] \\
\text { Installation of the stairs }\end{array}$ & 1,09 & 1,24 & 1,24 & 1,25 & 1,09 & 1,01 & 0,91 \\
\hline $\begin{array}{l}\text { Wyrównanie spoczników }\left[\mathrm{m}^{2} \cdot \mathrm{r}-\mathrm{g}^{-1}\right] \\
\text { Lining of the landings }\end{array}$ & 1,25 & 1,7 & 1,76 & 1,58 & 1,92 & 1,72 & 1,28 \\
\hline $\begin{array}{l}\text { Układanie spoczników }\left[\mathrm{m}^{2} \cdot \mathrm{r}_{-} \mathrm{g}^{-1}\right] \\
\text { Tiling of the landings }\end{array}$ & 1,19 & 1,17 & 1,24 & 1,23 & 1,19 & 0,87 & 1,07 \\
\hline
\end{tabular}

${ }^{a}$ Piątek, po którym następuje pracująca sobota (sobota jest ostatnim pracującym dniem tygodnia) - Friday before working Saturday (Saturday is the last working day of the week).

${ }^{\mathrm{b}}$ Piątek, który jest ostatnim dniem pracy w tygodniu roboczym - Friday is the last working day of the week.

Przedstawione w tabeli 4 wyniki badań zostały uśrednione. Najkorzystniejszym dniem okazała się środa, natomiast najgorszym - sobota. Przypisano im w związku z tym przynależność do zbioru wysokich wydajności $\left(\mu_{A}(x)\right)$, odpowiednio 1 i 0 . Pozostałym dniom tygodnia przyporządkowano proporcjonalne wartości zgodnie $\mathrm{z}$ formułą:

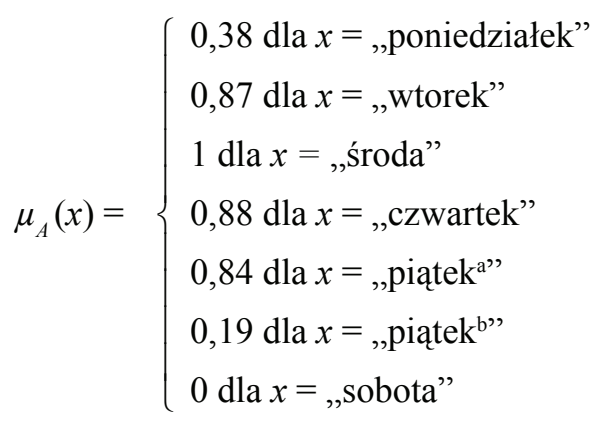

Inne podejście do parametryzacji czynników wpływających na wydajność pracy robotników budowlanych zaprezentowano dla wieku pracownika. Badania (Rowiński, 1982; Taylor, 2006; Naegele i Walker, 2006) dowodzą, że najlepszy pod względem uwarunkowań fizycznych wiek pracownika wynosi 26-27 lat. Nie można 
do tych informacji podejść jednak bezkrytycznie, ponieważ inna publikacja (Zawadzki, 2009) dowodzi, że pracodawcy chętnie poszukują osób zarówno w wieku 27 lat, jak i 35 czy 45. Dopiero po przekroczeniu tej granicy odsetek poszukiwanych pracowników zaczyna spadać i stabilizuje się na poziomie 55 lat. Powyżej tej granicy pracodawcy niechętnie chcą zatrudniać. Opisane zjawisko wiąże się z tym, że pracownicy po skończeniu 27 roku życia, mimo że zaczynają powoli słabnąć pod względem fizycznym, mają duże doświadczenie zarówno zawodowe, jak i życiowe, które pozwala im pracować na konkurencyjnym poziomie. Mając na uwadze polskie prawo pracy, które dopuszcza zatrudnienie pracownika po ukończeniu 16 lat, w niniejszym artykule określono funkcję przynależności czynnika wiek do zbiorów wysokich wydajności:

$$
\mu_{A}(x)=\left\{\begin{array}{l}
0 \text { dla } x \leq 16 \text { i } x \geq 55 \\
\frac{x-16}{10} \text { dla } 16<x<26 \\
\frac{55-x}{10} \text { dla } 45<x<55 \\
1 \text { dla } 16 \leq x \leq 45
\end{array}\right.
$$

Interpretację graficzną tej przynależności przedstawiono na rysunku 2.

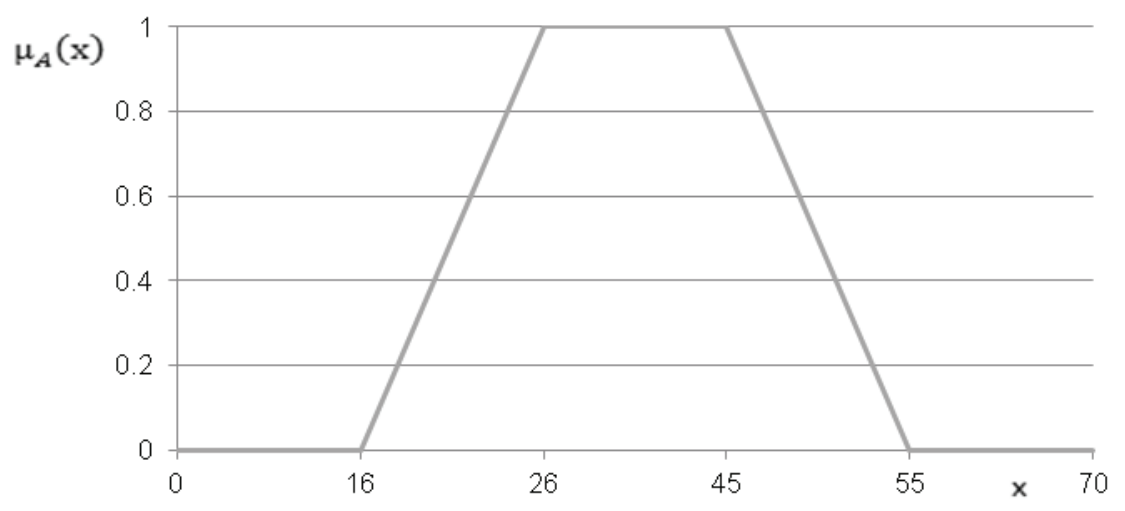

Rys. 2. Graficzna interpretacja rozmyta wartości funkcji przynależności do zbiorów wysokich wydajności dla czynnika wiek pracownika (opracowanie własne)

Fig. 2. Graphic interpretation of the fuzzy function for the collection of high performance for the medium age of the employee (authors`own elaboration)

W tym rozdziale zostały zaprezentowane trzy zupełnie różne podejścia do parametryzacji czynników. Ich wspólną cechą jest wykorzystanie założeń teorii zbiorów rozmytych do oceny wpływu czynnika na wydajność pracy robotników budowlanych. Konieczność zastosowania różnych podejść jest związana bezpośrednio z różnicami w jednostkach miary poszczególnych czynników. W analogiczny sposób można sparametryzować dowolny zidentyfikowany czynnik. Zdaniem autora jest to bardzo ważny krok służący do budowy matematycznego modelu wydajności czasu pracy. 


\section{PODSUMOWANIE}

W artykule przedstawiono problematykę badania wydajności czasu pracy, z uwzględnieniem czynników na nią wpływających. Pokazano trzy zasadnicze problemy związane z tym zagadnieniem. Należą do nich: różne definicje pojęcia wydajności pracy, odmienne klasyfikacje czynników oraz trudności z matematycznym opisaniem samych czynników. Przedstawione podejście jest pierwszym krokiem do budowy matematycznego modelu, który mógłby opisywać wydajność pracy robotników budowlanych, uzależniając ją od czynników. Należy jednak zwrócić uwagę na ograniczenia możliwości wykorzystania przedmiotowego podejścia $\mathrm{z}$ uwagi na postępującą automatyzację budownictwa w przypadku części robót.

\section{PIŚMIENNICTWO}

Chao, L. C. (2007). Fuzzy logic model for determining minimum bid markup. Computer - Aided Civil and Infrastructure Engineering, 22, 449-460.

Ćwiklicki, M. (2011). Współczesne oblicza tayloryzmu. W J. Czekaj i M. Lisiński (red.), Rozwój koncepcji i metod zarzqdzania. (strony 135-157). Kraków: Wydawnictwo Fundacji Uniwersytetu Ekonomicznego w Krakowie.

Dyżewski, A. (1989). Technologia i organizacja budowy. Warszawa: Arkady.

Gatignon, H. (2003). Statistical analysis of management data. New York: Springer-Verlag.

Główny Urząd Statystyczny, (2016). Wskaźniki zrównoważonego rozwoju. Moduł krajowy. Wydajność pracy. Katowice: Urząd Statystyczny w Katowicach.

Griffin, R. W. (2004). Podstawy zarzqdzania organizacjami. Warszawa: Wydawnictwo Naukowe PWN.

Hoła, B. i Mrozowicz, J. (2003). Modelowanie procesów budowlanych o charakterze losowym. Wrocław: Dolnośląskie Wydawnictwo Edukacyjne.

Hsie, M. (2009). A model used in creating a work-rest schedule for labores. Automation in Construction, 18, $762-769$.

Ibadov, N. i Kulejewski, J. (2010). Rozmyte modelowanie czasów wykonania robót budowlanych w warunkach niepewności. Czasopismo Techniczne. Budownictwo, B-1, 139-155.

Kieżun, W. (1980). Wstę do teorii organizacji i zarzqdzania. Warszawa: Wydawnictwo Uniwersytetu Warszawskiego.

Konior, J. (2007). Przedsięwzięcia i procesy budowlane w kategoriach zbiorów rozmytych. W O. Kapliński (red.), Metody i modele badań w inżynierii przedsięwzięć budowlanych. (strony 249-284). Warszawa: PAN.

Koźmiński, A. i Piotrowski, W., red. (1999). Zarzq̨zanie. Teoria i praktyka. Warszawa: Wydawnictwo Naukowe PWN.

Malara, J. (2014). Badania ilościowego aspektu czasu pracy robotników budowlanych. Przeglad Budowlany, 6, 32-35.

Naegele, G. i Walker, A. (2006). A guide to good practice in age management. European Foundation for the Improvement of Living and Working Conditions.

Plebankiewicz, E. (2012). Procedura prekwalifikacji wykonawców robót budowlanych. Kraków: Wydawnictwo PK.

Plebankiewicz, E., Juszczyk, M. i Malara, J. (2014). Identyfikacja i ocena czynników wpływających na wydajność pracy robotników budowlanych. Przegląd Naukowy Inżynieria i Ksztattowanie Środowiska, 65, 271-278.

Radziszewska-Zielina, E., Sobotka, A., Plebankiewicz, E. i Zima, K. (2013). Wstępna identyfikacja i ocena parametrów wpływających na wydajność układu operator-maszyna do robót ziemnych. Budownictwo i Architektura, 12(1), 53-60.

Rowiński, L. (1982). Organizacja produkcji budowlanej. Warszawa: Wydawnictwo Arkady.

Staworzyński, P. (2017). Pobrano z lokalizacji: http://www.Staworzynski.Com/Artykuly/Wydajnosc-Produktywnosc?P1_ Wydajnosc-I-Produktywnosc\%2c118=\#Produktywno\%C5\%9b\%C4\%87, Ostatni dostęp: 13.01.2017.

Tah, J. H. M. i Carr, V. (2000). A proposal for construction project risk assessment using fuzzy logic. Construction Management and Economics, 18, 491-500.

Taylor, P. (2006). Employment initiatives for an ageing workforce in the eu15. Dublin: European Foundation for the Improvement of Living and Working Conditions.

Zawadzki, K. (2009). Zarządzanie wiekiem w organizacjach gospodarczych. W Z. Wiśniewski (red.), Zarzqdzanie wiekiem w organizacjach wobec procesów starzenia się ludności. (strony 11-39). Toruń: Dom Organizatora. 


\section{ASSUMPTIONS FOR MODEL OF LABOR PRODUCTIVITY OF CONSTRUCTION WORKERS}

\section{SUMMARY}

The paper examines issue of productivity time among construction workers, which depends on different factors. Differences between various ways of defining the work productivity were described. According to the author the most advantageous definition is based on a comparison of the achieved and assumed work effects. Existing classification of factors affecting work productivity and their evaluation in terms of versatility were also presented. In a direct comparison one of the classifications turned out to be the most universal. As a result an approach to mathematical parameterization of the factors affecting the performance of construction workers was proposed.

Key words: model, work performance, construction workers, factors 